\title{
Perceived work-related stress and coping strategies among critical care nurses - A preliminary study from Sri Lanka
}

\author{
Sutharshan $\mathbf{N}^{1}$, Nufais $\mathbf{M B}^{2}$, Shrirajanie $\mathbf{N}^{2}$, Abdul Munaff $\mathbf{M H}^{3}$, Kisokanth $\mathbf{G}^{4}$
}

${ }^{1}$ Divisional Hospital, Maruthamunai, Eastern Province, Sri Lanka, ${ }^{2}$ Ashraff Memorial Hospital, Kalmunai, Eastern Province, Sri Lanka, ${ }^{3}$ Divisional Hospital, Iragamam, Eastern Province, Sri Lanka, ${ }^{4}$ Department of Clinical Nursing, Faculty of Nursing, University of Colombo, Sri Lanka

\section{ABSTRACT}

Introduction: Work-related stress has become a major concern among the nurses over the years. Nurses experience a high level of work-related stress when work demands exceed their ability to cope. The study aimed to assess the perceived work-related stress level and coping strategies among nurses working in Critical Care Units at a Base Hospital in the Eastern Province of Sri Lanka.

Methods: A cross sectional descriptive study was conducted among all staff nurses (105) working in critical care units. Data were collected using a validated and pre-tested self-administered questionnaire. A Perceived Stress Scale developed by Cohen et al. (1983) and validated in Sri Lanka was used to assess the work-related stress, along with coping strategies. Data were analyzed by descriptive statistics using SPSS version 21.

Results: Around $30 \%$ of nurses had higher level of perceived stress while $45 \%$ had moderate level of perceived stress. Nearly $81 \%$ of nurses stated that religious activities are used as a common coping strategy. In addition, $96 \%$ of them used 'positive thinking' while $70 \%$ of them used 'time management' as the main coping strategy. Conclusion: The prevalence of work-related perceived stress among critical care nurses was high. Further, nurses use various emotion focused coping strategies such as regular engagement in religious activities and positive thinking and problem focused coping strategies such as time management and talk with friends/loved ones to overcome the work-related stress.

Key words: Coping strategies, Nurses, Sri Lanka, Stress, Time management

\section{Introduction}

he nursing profession is believed to be one of the highly stressful occupation worldwide. ${ }^{1}$ Nurses play a key role and encompass the largest workforce in any health care institution. Further, they act as direct caregivers who serve a hospital twenty-four

\section{DOI: https://doi.org/10.3126/ijosh.v11i2.36139}

Conflicts of interest: None

Supporting agencies: None

Date of submission: 30.03.2021

Date of acceptance: 13.06.2021

Date of publication: 20.06.2021

\section{Corresponding Author}

Dr. Gnanaselvam Kisokanth (PhD)

Senior Lecturer/ Head, Department of Clinical Nursing,

Faculty of Nursing,

University of Colombo, Sri Lanka

Tel.: +94772228330

Email: kiso@dnc.cmb.ac.lk

ORCID ID: https://orcid.org/0000-0002-5956-4463 hours a day, seven days a week, which gives nurses a unique perspective on both patient care and hospital operations. ${ }^{2}$ Nurses work long hours in hospitals, and the job is physically challenging. In addition, nurses deal with human suffering daily, and need a high level of vigilance to assure patient safety in an environment that is complex. Several studies have shown that nurses often face multiple sources for increased workrelated stress, including constant noise, interpersonal conflicts with other healthcare professionals, workload demands, role conflicts, dealing with death and dying, lack of resources, lack of support from co-workers and supervisors, patient aggressiveness or violence and increasing patient loads. ${ }^{3,4}$ All these factors can increase a nurse's perceived stress level and affect their health. ${ }^{5}$ Further, it was reported that critical care

\section{(c) (1) (8)}

This journal is licensed under a Creative Commons AttributionNon Commercial 4.0 International License. 
nurses experience more perceived stress than other nurses ${ }^{6,7}$ due to regular expectation of emergencies, high technological complexity, and concentration of severely injured and life-threatening patients subject to sudden changes in their general health status. ${ }^{8}$

Stress occurs when perceived demand exceed the individuals' coping abilities. Coping strategies help to moderate or buffer the impact of stressors on physical and psychological well-being. ${ }^{9}$ Further, coping strategies are used by individuals to alter their personal perception and behavior in response to the conflicts raised from their working environment due to increased stress level. Therefore, nurses with higher levels of coping abilities to cope with professional challenges are more likely to succeed in the nursing profession, work hard, and perform their job tasks effectively. ${ }^{10,11,12}$ Coping strategies can be emotion focused or problem focused. Emotion-focused coping includes all the regulative efforts to diminish the emotional consequences of stressful events, while problem-focused coping includes all the active efforts to manage stressful situations and alter a troubled person-environment relationship to modify or eliminate the sources of stress via individual behavior. ${ }^{13}$

Further, perceived stress and coping abilities influence the health and work performance of the nurses. Perceived stress diminishes both general quality of life and person's sense of well-being. According to Alenezi (2018), work-related stress in the working environment significantly affects the performance of nurses and organizations. ${ }^{14}$ Stress may provoke poor nursing and poor administrative performance, leading to substandard quality of patient care.

Even though, many studies have been conducted in many parts of the world, we could not identify any reported studies conducted to assess the perceived stress level along with coping strategies among critical care nurses, especially in Eastern province of Sri Lanka. Thus, this study aimed to assess the workrelated perceived stress level and coping strategies among nurses working in Critical Care Units at Ashraff Memorial Hospital, Kalmunai as a preliminary study.

\section{Methods}

A cross-sectional descriptive study was conducted among all nurses who work at all critical care units, such as Intensive Care Unit (ICU), High Dependency Unit (HDU), Neonatal Intensive Care Unit (NICU),
Preliminary Care Unit (PCU), and Operation Theatre (OT), in Ashraff Memorial Hospital, Kalmunai. Both male and female nurses working in all critical care units were included and nurses who were on long term leave (maternal leave, accident leave, wedding leave and etc.) during the data collection were excluded from the study. A total of 105 nurses who met the inclusion were recruited for the study. Study was conducted in later part of 2018 for a period of six months and data collection was carried out using self- administered questionnaire (SAQ). Work-related stress among nurses was assessed using Perceived Stress Scale (PSS) developed by Cohen et al. (1983). ${ }^{15}$ It is a standard tool which is validated and used in Sri Lanka previously by llankoon et al. (2014). ${ }^{16}$ It is 5 point Likert scale which ranges from 0 (never) to 4 (very often). The total score ranges from $0-40$ with a highest score indicating a higher perceived stress. The level of perceived stress was categorized as follows; 0-13 low stress, 14-26 - moderate stress and 27-40 - high perceived stress. Based on the published literature on coping strategies, common coping strategies were assessed among participants which were listed in the questionnaire and participants were asked to choose.

Data collection was carried out during their off time, rest time and after ward-rounds without interrupting patient's care and ward routine activities. Data collection was conducted separately among the participants and each participant spent approximately 20-30 minutes to fill the questionnaire.

Collected data were coded and entered into SPSS (Version-21). Descriptive statistics were used to assess the stress and coping strategies used by the nurses.

The ethical clearance was obtained from the Ethics Review Committee, Faculty of Healthcare Sciences, Eastern University, Sri Lanka (ERC/2018/49). The participants were comprehensively informed about the purpose and nature of the study using the information sheets, and written informed consent was obtained from all participants.

\section{Results}

Nearly half of the participants were in the age group of $31-40$ years $(46 \%)$ and majority $(74 \%)$ were females. Nearly $47 \%$ of them had a total of $201-300$ duty hours per month. Around $50 \%$ of them stated that they have more workload in their unit and $40 \%$ them mentioned that they received good support from their superior. 
Around $30 \%$ of nurses $(n=31)$ had higher perceived stress level while $46 \%$ of them $(n=48)$ had moderate stress level based on the perceived stress scale

Nearly $81 \%$ of them suggested that regular engagement in religious activities is the main coping strategy while $96 \%$ suggested that positive thinking was used to recover them from stressful events.

Nearly $69 \%$ of participants stated that time management and talk with friends/loved ones were the common problem-based coping strategies used by them to reduce their work-related stress.

Table 1: Socio-demographic and work-related details of participants $(n=105)$

\begin{tabular}{lcc}
\hline Variables & Category & $\mathbf{n ~ ( \% )}$ \\
\hline Age & $21-30$ Years & $43(41.0)$ \\
& $31-40$ Years & $48(45.7)$ \\
& $41-50$ Years & $14(13.3)$ \\
Gender & Female & $78(74.3)$ \\
Marital status & Male & $27(25.7)$ \\
Duty hours per month & Married & $69(65.7)$ \\
& Unmarried & $36(34.3)$ \\
& $101-200$ & $15(14.3)$ \\
Workload in the unit & $201-300$ & $49(46.7)$ \\
& $301-400$ & $41(39.0)$ \\
\hline Support of superior & Yes & $52(49.5)$ \\
& No & $32(30.5)$ \\
& Neutral & $21(20.0)$ \\
\hline Social support & Poor & $35(33.3)$ \\
& Gairly & $21(20.0)$ \\
& Good & $42(40.0)$ \\
& Very good & $07(6.7)$ \\
\hline \multirow{2}{*}{ Poor } & $57(54.3)$ \\
& Good & $37(35.2)$ \\
& Very good & $11(10.5)$ \\
\hline
\end{tabular}

\section{Discussion}

This preliminary study was conducted to determine the work-related perceived stress level among the nurses working at all critical care units in Ashraff Memorial Hospital in Kalmunai, Sri Lanka. The study revealed that nearly $30 \%$ of nurses had a higher perceived stress level, while $46 \%$ had moderate stress. Similarly, a study conducted among ICU/CCU nurses in Jordan ${ }^{17}$ and in United States ${ }^{18}$ reported that most of the nurses experienced higher levels of work-related stress. Critical care units are one of the most stressful clinical areas of a hospital. Critical care nurses often experience
Table 2: The level of the perceived stress of the participants

\begin{tabular}{lc}
\hline Perceived Stress Level & $\mathbf{n}(\%)$ \\
\hline Higher stress level & $31(29.5)$ \\
Moderate stress level & $48(45.7)$ \\
Lower stress level & $26(24.8)$ \\
\hline
\end{tabular}

Table 3: Emotion- focused coping strategies used by nurses $(n=105)$

\begin{tabular}{lc}
\hline${ }^{*}$ Coping strategies & $\mathbf{n ~ ( \% )}$ \\
\hline Engage in religious activities & $85(80.9)$ \\
\hline Listen to music & $81(77.1)$ \\
\hline Positive thinking & $101(96.2)$ \\
\hline Relaxation practice & $55(52.4)$ \\
\hline Exercise regularly & $57(54.3)$ \\
\hline Eating healthy food & $70(66.7)$ \\
\hline Time for hobbies and relaxation & $68(64.8)$ \\
\hline Practice enough rest and sleep & $60(57.1)$ \\
\hline Practice breathing exercises & $68(64.8)$ \\
\hline
\end{tabular}

*- Multiple responses were allotted

Table 4: Problem- focused coping strategies used by nurses $(n=105)$

\begin{tabular}{lc}
\hline${ }^{*}$ Coping strategies & $\mathbf{n ~ ( \% )}$ \\
\hline Create a to do list & $61(58.1)$ \\
\hline Assertiveness & $34(32.4)$ \\
\hline Time management & $73(69.5)$ \\
Set limits & $68(64.8)$ \\
\hline Talking with peers/loved one & $72(68.6)$ \\
Engage in problem-solving & $68(64.8)$ \\
\hline
\end{tabular}

*- Multiple responses were allotted

higher work-related stress, generally due to fear of committing errors in highly technical and complicated nursing interventions and increased workloads due to understaffing. In addition, critical care nurses are challenged with a lot of difficult situations every day. Prolonged and constant stress lead to harmful effect on nurses' health, and further leads to organizational inefficacy and less job satisfaction ${ }^{19}$. Thus, nurses need to accept that there are situations which are beyond their control and responding to uncontrollable situations in a way that nurses thereby reducing their work-related stress.

Critical care nurses are often exposed to one of the stressors throughout the day, and if an appropriate coping strategy is not used, it may lead to physical, psychological, and social consequences in their life. Coping strategies are essential when attempting to 
deal with the stress that nurses face daily. Further, developing coping strategies is an essential nursing skill to be used in stressful situations. In the present study, critical care nurses reported different types of emotion/problem focused coping strategies, in order to handle the stressful situations.

Among the different emotion-focused coping strategies reported by the critical care nurses, positive thinking was rated as a most frequent coping strategy used, especially during the stressful situations. Positive thinking can be effective in improving the function and reducing job stress of nurses, and has an impact on the behavior of people in terms of coping with stressful experiences and overcoming them. ${ }^{20}$ In addition, engaging in religious activities was also reported as another common coping strategies among the nurses. Religious activities and a healthy spiritual activity would help improve the perception of nurses towards their working environment. Engaging in religious activities and spiritual interventions have proven to be effective means of coping with physical and mental stresses. ${ }^{21}$ Further, engaging in religious activities provides resources that foster coping with stressful events and supports positive emotions. ${ }^{22}$

In addition, several problem-focused coping strategies have also been reported by the nurses in the current study. Engaging in problem solving strategy has been identified as one of the best ways to cope with work-related stress among critical care nurses. It was highlighted that problem solving is one of the most effective ways to deal with stress which involves focusing on altering or managing the problem. ${ }^{23}$ Similarly, different studies conducted among nursing

\section{References}

1. Najimi A, Goudarzi AM, Sharifirad G. Causes of job stress in nurses: A cross-sectional study. Iran J Nurs Midwifery Res. 2012;17(4):301-5.

2. Practice Standards for Regulated Members, 2013. Available at: https://nurses.ab.ca/docs/default-source/ document-library/standards/practice-standardsfor-regulated-members.pdf?sfvrsn=d4893bb4_16, Accessed on $20^{\text {th }}$ January 2019.

3. King KA, Vidourek R, Schwiebert M. Disordered eating and job stress among nurses. Journal of Nursing Management, 2009; 17(7):861-9.

4. Glazer S and Gyurak A. Sources of occupational stress among nurses in five countries. International Journal of Intercultural Relations, 2008; 32(1): 49-66 students reported that problem solving is the most utilized coping strategy to cope with their stress. ${ }^{24,25}$

Non-response bias was the limitation of the study as we did not get $100 \%$ respondent rate. Since selfadministered questionnaire was administered, critical care nurses are probably less likely to respond it since they do not have free time to fill as they are always busy with caring the life-threatening cases.

\section{Conclusions}

The prevalence work-related perceived stress was high among the nurses at all critical care units in Ashraff Memorial Hospital, Kalmunai, Sri Lanka. Most of the nurses had used different emotion- focused coping strategies such as positive thinking, engaging in the religious activities, listening to music and problem focused coping strategies such as time management, talking with loved one for reducing work-related stress. These findings can set a firm basis for recognizing the level of work-related stress among nurses and their coping strategies to overcome the stress.

Primarily, the policy makers and administrators should take measures to reduce work-related stress associated with the shortage of staff, poor physical environment, inadequate training for staff and lack of facilities. In addition, nurse educators can develop plans to enhance nurses awareness on coping strategies for their stress reduction.

\section{Acknowledgement}

Authors wish to thank the participants for providing the information.

5. Scott L, Hwang W, Rogers A. The Impact of Multiple Care Giving Roles on Fatigue, Stress, and Work Performance among Hospital Staff Nurses. Journal of Nursing Administration 2006;36(2):86-95.

6. McMeekin DE, Hickman RL, Douglas SL, Kelley CG. Stress and coping of critical care nurses after unsuccessful cardiopulmonary resuscitation. Am J Crit Care 2017;26(2):128-35.

7. Foster GWD, Froehling S. Psychological response to situational stress in intensive and non intensive nursing. Heart Lung 1972;1(6):793-6.

8. Preto VA, Pedrão LJ. O estresse entre enfermeiros que atuam em Unidade de Terapia Intensiva [Stress among nurses who work at the intensive care unit]. Rev Esc Enferm USP. 2009 Dec;43(4):841-8. 
9. Straub, R. O. (2007). Health psychology: A biopsychosocial approach (2nd ed.). New York, NY: Worth.

10. van der Heijden BIJM, Demerouti E, Bakker AB. Work-home interference among nurses: reciprocal relationships with job demands and health. Journal of Advanced Nursing 2008; 62(5),572-84.

11. Ilhan MN, Durukan E, Taner E, Maral I, Bumin MA. Burnout and its correlates among nursing staff: questionnaire survey. Journal of Advanced Nursing 2008; 61(1), 100-6.

12. Dominguez-Gomez E, Rutledge DN. Prevalence of secondary traumatic stress among emergency nurses. Journal of Emergency Nursing 2009; 35(3):199-204.

13. Schoenmakers EC, van Tilburg TG, Fokkema T. Problem-focused and emotion-focused coping options and loneliness: how are they related?. Eur J Ageing (2015) 12:153-61

14. Alenezi AM, Aboshaiqah A, Baker O. Work-related stress among nursing staff working in government hospitals and primary health care centres. Int J Nurs Pract 2018;24(5):e12676.

15. Cohen S, Kamarck T, Mermelstein R. A global measure of perceived stress. Journal of health and social behavior 1983; 24: 385-96.

16. Ilankoon IMPS, Warnakulasooriya SSP. Perceived stress and associated factors among BSC nursing undergraduates in University of Sri Jayewardenepura, Sri Lanka. Proceedings of International Research Conference, General Sir John Kotelawala Defence University, Sri Lanka, 2014. http://ir.kdu.ac.lk/bitstream/handle/345/1490/h012. pdf? sequence $=1$ \&isAllowed $=y$.
17. Alhalaiqa F, Dweik G. Perceived stress in nurses: A comparative study. Global J Health Sci. 2017; 9(6): 195-203.

18. Oyeleye O, Hanson P, O'Connor N, Dunn D. Relationship of workplace incivility, stress, and burnout on nurses' turnover intentions and psychological empowerment. J Nurs Adm. 2013; 43(10): 536-42.

19. Isa $K Q$, Ibrahim MA, Abdul-Manan $H H$, Mohd-Salleh $\mathrm{ZH}$, Abdul-Mumin KH, Rahman HA. Strategies used to cope with stress by emergency and critical care nurses. Br J Nurs. 2019;28(1):38-42.

20. Augusto-Landa JM, Pulido-Martos M, Lopez-Zafra E. Does perceived emotional intelligence and optimism/ pessimism predict psychological well being?. Journal of Happiness Studies 2011; 12(3):463-74.

21. Cruz JP, Alshammari F, Alotaibi KA, Colet PC. Spirituality and spiritual care perspectives among baccalaureate nursing students in Saudi Arabia: A cross-sectional study. Nurse Educ Today, 2017; 49: 156-162.

22. Cruz JP, Alquwez N, Albaqawi HM, Alharbi SM, Moreno-Lacalle RC. Nurses' perceived spiritual climate of a hospital in Saudi Arabia. Int Nurs Rev. 2018 Dec;65(4):559-566.

23. Chinaveh $M$. The effectiveness of problem-solving on coping Skills and Psychological Adjustment. Procedia - Social and Behavioral Sciences 2013; 84:4 - 9.

24. Al-Zayyat AS, Al-Gamal E. Perceived stress and coping strategies among Jordanian nursing students during clinical practice in psychiatric/mental health courses. Int J Ment Health Nurs. 2014;23:326-35

25. Al-Gamal E, Alhosain A, Alsunaye K. Stress and coping strategies among Saudi nursing students during clinical education. Perspect Psychiatr Care. 2018;54:198-205. 